\title{
The opioid crisis: a contextual, social-ecological framework
}

\author{
Mohammad S. Jalali ${ }^{1,2^{*}}$ (D, Michael Botticelli ${ }^{3}$, Rachael C. Hwang ${ }^{2}$, Howard K. Koh ${ }^{4,5}$ and R. Kathryn McHugh ${ }^{1,6}$
}

\begin{abstract}
The prevalence of opioid use and misuse has provoked a staggering number of deaths over the past two and a half decades. Much attention has focused on individual risks according to various characteristics and experiences. However, broader social and contextual domains are also essential contributors to the opioid crisis such as interpersonal relationships and the conditions of the community and society that people live in. Despite efforts to tackle the issue, the rates of opioid misuse and non-fatal and fatal overdose remain high. Many call for a broad public health approach, but articulation of what such a strategy could entail has not been fully realised. In order to improve the awareness surrounding opioid misuse, we developed a social-ecological framework that helps conceptualise the multivariable risk factors of opioid misuse and facilitates reviewing them in individual, interpersonal, communal and societal levels. Our framework illustrates the multi-layer complexity of the opioid crisis that more completely captures the crisis as a multidimensional issue requiring a broader and integrated approach to prevention and treatment.
\end{abstract}

Keywords: opioids, opioid use disorder, social-ecological framework

\section{Background}

The alarming rise in opioid misuse over the past two and a half decades has resulted in a public health crisis, characterised most prominently by a dramatic increase in drug overdose deaths. In 2017, approximately 12 million Americans misused opioids [1] and more than 47, 000 people died of opioid overdose [2]. This overdose fatality rate reflects an increase of $345 \%$ between 2001 and 2016 [3], with particularly steep annual increases in overdose fatalities since 2015. The growing opioid misuse issue was recognised as a national public health

This comment refers to the article available at https://doi.org/10.1186/ s12961-020-00598-6.

* Correspondence: msjalali@mgh.harvard.edu

${ }^{1}$ Harvard Medical School, Harvard University, Boston, MA, United States of America

${ }^{2}$ Institute for Technology Assessment, Massachusetts General Hospital, 101 Merrimac St, Suite 1010, Room 1032, Boston, MA 02114, United States of America

Full list of author information is available at the end of the article emergency by the United States Department of Health and Human Services in 2017.

Over the last several years, opioid misuse gained the attention of scholars, researchers, health professionals and politicians [4]. Many have called for a broad public health approach, but the full breadth of such a strategy has not yet been articulated or realised. While various interventions have been implemented over time, they have generally been insufficient to slow the growth of non-fatal and fatal overdoses at a national level [5]. Interventions that only target a single aspect of the issue, such as restricting opioid supply, will not be sufficient to ameliorate the opioid epidemic. This is further complicated by the rapidly evolving nature of the epidemic. For example, the widespread availability of fentanyl and fentanyl analogues beginning around 2013 has resulted in a steep escalation of overdose death rates, even as other public health indicators (e.g. prescription opioid misuse) have begun to improve.

(c) The Author(s). 2020 Open Access This article is licensed under a Creative Commons Attribution 4.0 International License, which permits use, sharing, adaptation, distribution and reproduction in any medium or format, as long as you give appropriate credit to the original author(s) and the source, provide a link to the Creative Commons licence, and indicate if changes were made. The images or other third party material in this article are included in the article's Creative Commons licence, unless indicated otherwise in a credit line to the material. If material is not included in the article's Creative Commons licence and your intended use is not permitted by statutory regulation or exceeds the permitted use, you will need to obtain permission directly from the copyright holder. To view a copy of this licence, visit http://creativecommons.org/licenses/by/4.0/ The Creative Commons Public Domain Dedication waiver (http://creativecommons.org/publicdomain/zero/1.0/) applies to the data made available in this article, unless otherwise stated in a credit line to the data. 
Furthermore, although the years of steeply escalating fatalities have brought newfound attention to the harms of opioid misuse, this problem is not new. Opioid use disorder (OUD) is a disabling disorder with high levels of morbidity and mortality that has devastated families and communities for decades. Although the introduction of agonist treatments in the 1970s brought critical relief to many people suffering from this illness, few people received any treatment even prior to the current crisis [6], while increasing criminalisation of drug use diverted a high proportion of this population to the criminal justice system. Thus, the inadequate public health and societal response to the harms of opioids is longstanding and new and expanded responses are sorely needed. The complexity of the crisis is represented by the multiple spheres of influence derived from individual factors, interpersonal relationships, and community and societal influences, indicating the necessity of a broader and a more integrated approach that includes prevention, treatment and overdose rescue interventions in addition to supply reduction strategies.

In this paper, we present a social-ecological framework as an important step to conceptualise the complexity of the opioid epidemic. This framework can help inform the design of impactful interventions to curb the opioid crisis. We present our framework and provide a brief overview of the literature informing its components.

\section{Social-ecological framework}

Our social-ecological framework, illustrated in Fig. 1, depicts the major risk factors for opioid misuse on four main levels: the individual, interpersonal, communal and societal (see Additional file 1 for our use of the term 'framework'). Each of these levels must be acknowledged to develop multifaceted and effective interventions to mitigate the opioid crisis. Following social ecological paradigms [7], prior research has presented frameworks for substance use [8] in general and alcohol use [9] in particular. While there are similarities among these frameworks and ours, there are essential factors related to opioid misuse, such as the existence of both legal (i.e. via legitimate prescription) and illegal supply sources and the availability of highly effective medications, that we discuss in this article. In the following sections, we provide a brief overview of how these levels of factors contribute to the opioid epidemic.

\section{Individual level}

Individual-level factors in opioid misuse and OUD span sociodemographic, health and mental health, biological, and psychosocial domains. Individual factors can influence every aspect of the spectrum of opioid use and misuse, including the likelihood of exposure to opioids, initiation of opioid misuse, the development and maintenance of OUD, entry to and engagement in treatment, and relapse following an attempt to quit. These factors

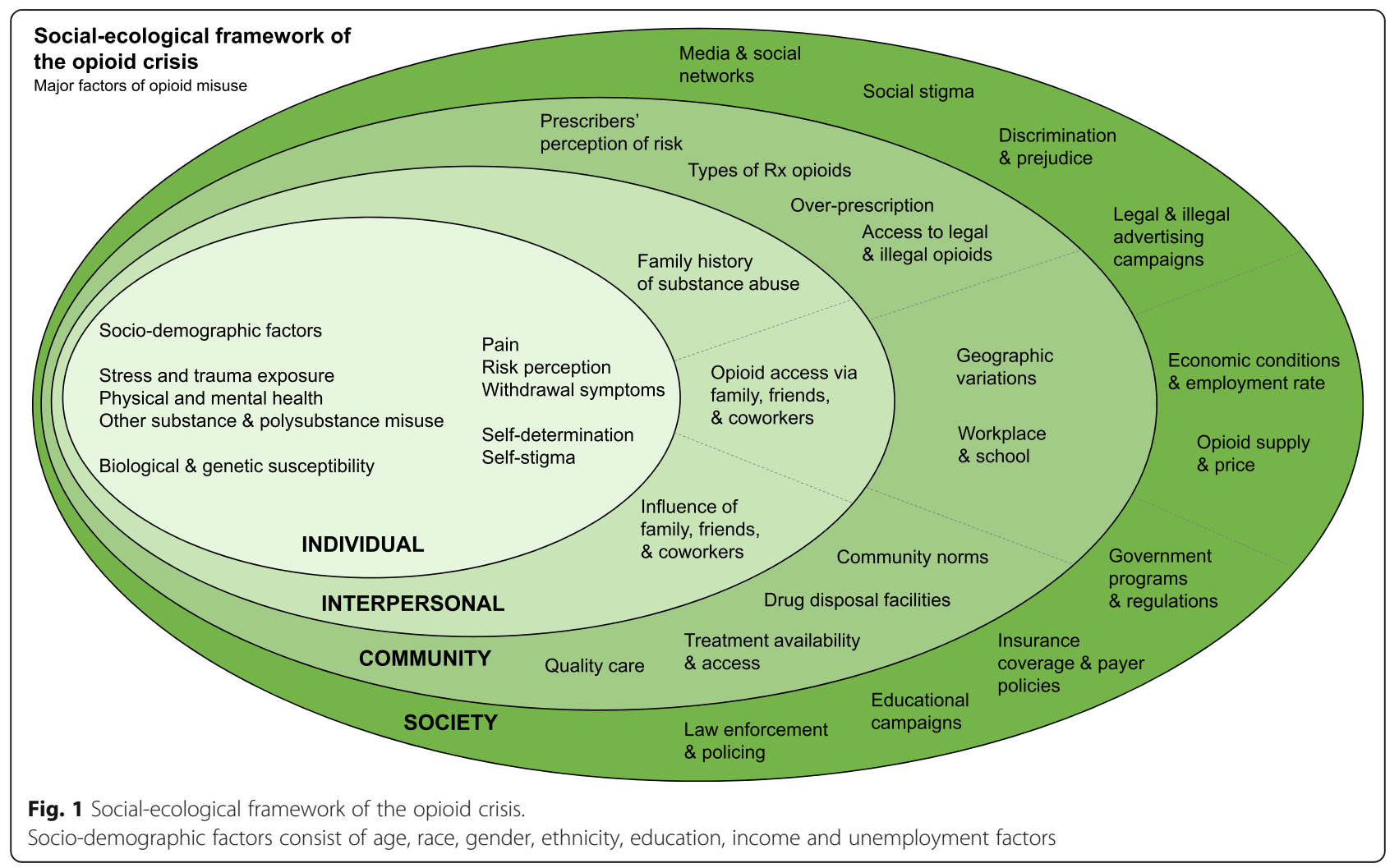


are complex, often interact and, in some instances, can be both a cause and consequence of opioid misuse (e.g. financial strain).

Many sociodemographic factors interact with opioid misuse, with implications for identifying at-risk populations. Opioid misuse peaks in early adulthood (approximately 18-25 years) [10]. Early initiation of opioid misuse is a significant risk factor for the development of OUD [11] and, thus, adolescence and young adulthood are key risk periods for opioid misuse. Gender can also play a role in risk for opioid misuse. For example, women are more likely than men to receive an opioid prescription [12, 13] and sex differences in the pharmacological effects of opioids have been demonstrated [14]. Critically, opioids are known teratogens and untreated OUD presents risks to both neonatal and maternal outcomes [15].

Race also plays a complex role in the opioid epidemic. People identified as non-Hispanic white are more likely to receive an opioid prescription, increasing the risk of exposure via this route [16]. Disparities in healthcare for pain often leave pain untreated or undertreated in racial and ethnic minorities [17]. Although the opioid epidemic initially predominantly affected non-Hispanic whites [18], opioid overdose is rapidly increasing among racial minorities [19]. Race also impacts access to treatment; the vast majority of studies suggest, unsurprisingly, that racial and ethnic minority groups have less access to treatment. For instance, studies show that access to effective medication for OUD is lower in communities with higher African American and Hispanic populations [20, 21]. One study found that, among people in treatment for OUD, the vast majority did not receive agonist therapies and that opioid agonist prescriptions were modestly higher in black and Hispanic clients who used heroin relative to white clients [22]. Yet, many other studies suggest that racial and ethnic minorities face disparities in access to care such as delayed admissions to treatment and lower likelihood of receiving treatment $[18,23]$. Another essential component of the role of race in the opioid epidemic is the disproportionate arrest and incarceration of people of colour - we will discuss this further in the 'Societal level' section. Additionally, a wide array of health and mental health factors may increase the likelihood of risk for misuse, some of which overlap with those that increase the likelihood of a prescription (e.g. pain). Pain is a core element of the opioid crisis and the majority of people seeking treatment for prescription OUD report first using opioids for pain with a legitimate prescription [24]. Similarly, mental health factors are a significant contributor to opioid misuse. The majority of people with OUD also suffer from a mood or anxiety disorder [25] and psychiatric symptoms are associated with incident risk for prescription opioid misuse [26]. Additionally, a history of other substance misuse and other substance use disorders is a significant risk factor for opioid misuse; it is the most robust predictor of opioid misuse in people with chronic pain [27]. Similarly, polysubstance use increases the risk of opioid misuse [28] and recent research shows that it is highly prevalent among those with OUD [29].

A number of biological factors and genetic susceptibility can also predispose individuals to develop OUD. In addition to biological vulnerability to substance use disorders in general $[30,31]$, factors that influence the effects of opioids include genetic factors that alter the opioid receptors in the brain $[32,33]$. Once physiological tolerance is developed to an opioid, decreases in dose or removal of the medication will result in withdrawal symptoms [34]. Although these symptoms are not fatal, they are extremely aversive and a significant reason for continued opioid use and relapse in people with OUD [35]. Indeed, over the course of OUD, the primary reason for use tends to shift to avoiding/relieving withdrawal more than managing pain or feeling good [24].

In this section, we have highlighted some key individual-level factors; however, it should be noted that the they are not meant to be comprehensive. A wide range of other psychological and temperamental factors can also play a role in the opioid epidemic; these include factors such as impulsivity [36], self-stigma [37] and selfdetermination [38]. Readiness for change is also another factor that is associated with entry into treatment [39] and the change process during the treatment [40], although limited data suggest this may not be related to OUD treatment outcome [41]. Overall, there is an essential need for more research on the role of these and other similar psychosocial factors.

\section{Interpersonal level}

Family, friends and co-workers significantly shape the beliefs, attitudes and behaviours of individuals to influence the likelihood of individuals' initiation and misuse of substances [42-44]. A family history of substance use disorder can influence opioid misuse through both genetic and environmental factors. People who have a family member with OUD are 10 times more vulnerable to misuse and overdose on the drug themselves and youth witnesses of family member overdose are more prone to overdose themselves $[45,46]$. Individuals with a family history of opioid use are at a higher risk of suffering from symptoms of opioid dependence and becoming severely dependent [47]. This may be particularly important for women, for whom the risk of opioid misuse is higher when a spouse or partner misuses opioids [48]. Opioid misuse is also influenced by the accessibility to opioids from family, friends and/or co-workers. 
Approximately $70 \%$ of people who report non-medical opioid use reportedly obtained opioids from family members or close friends $[49,50]$. Co-workers can also be a source of opioids since about $69 \%$ of people who misuse opioids are employed and 10\% to $12 \%$ report drug use during working hours $[51,52]$.

Interpersonal relationships influence the actions of individuals to use opioids and seek treatment. Parental disapproval of drugs discourages substance use and families are often the first to detect drug misuse because of their awareness of substance history [44, 53]. Studies show that family support of recovery can increase the likelihood of receiving treatment $[49,54]$. The emotional support from social supports can increase medication adherence and motivate patients during their treatment sessions $[53,55]$.

\section{Communal level}

The third level of our framework considers the communal settings and their contributions to opioid-related risks [56]. The community and the immediate context in which individuals live affect their daily behaviours in significant ways. Variables such as geographic conditions, treatment accessibility, medication disposal services, workplace environment, prescribers' perception of risk, over-prescription of opioids or under-treatment of pain, types of prescription opioid formulations available, community norms, and access to legal and illegal opioids are major risk factors that can perpetuate opioid misuse.

Between 2006 and 2017, approximately 224 million opioid prescriptions were filled annually in the United States, which is almost enough to distribute across the entire United States population [57]. Over-prescription of opioids has been influenced by several interacting factors. Oftentimes, physicians' insufficient pain management training and knowledge on opioid misuse risk contribute to their inability to safely prescribe opioids, implement and interpret risk assessments, detect addiction, and facilitate discussions with patients [58-60]. Furthermore, prescribers who overestimate the benefits and underestimate the danger of opioids are likely to contribute to over-prescription by providing months' worth of medication when only a few days may be needed for pain management $[61,62]$. The institution of guidelines (e.g. the Centers for Disease Control and Prevention's Guideline for Prescribing Opioids for Chronic Pain) and other interventions to improve prescribing practices has resulted in decreases in opioid prescribing [63], with reductions occurring since 2010 [57].

Over-prescription was also influenced by pharmaceutical marketing campaigns that falsely marketed opioids as non-addictive and "create[d] value" for doctors by offering monetary compensations [64]. Doctors who refused to prescribe opioids to patients were labelled as 'opiophobic' [65]. These incentives include sponsored meals, speaking fees, travel expenses and education [66]. Although only $7 \%$ of opioid-prescribing physicians received gifts from drug companies, they were more likely to prescribe opioids to their patients than doctors who did not benefit from the incentive [66]. Increases in prescriptions may have also reflected unintended consequences of advocacy for the improved treatment of acute and chronic pain in the 1990s, which resulted in regulatory changes requiring the assessment of pain as the 'fifth vital sign'.

Formulations of opioids also play a role in opioid misuse. Standard opioid pills can be crushed to attain a more rapid effect via routes of administration such as intranasal or intravenous [67]. Despite the lack of sufficient supporting evidence for the efficacy of abusedeterrent drugs in preventing misuse, the United States Food and Drug Administration has supported the development of such types of prescription opioids to address the growth in opioid-related abuse and deaths $[68,69]$. The misconception that abuse-deterrent opioids are a panacea dangerously marks the issue as a pharmaceutical problem rather than a complex one integrated by biological, psychological and social challenges [67]. Furthermore, abuse-deterrent opioids do not solve the longstanding problem of heroin and other illicitly produced opioids.

The illicit market is another significant source of misused opioids. Heroin is cheap and widely available in most regions in the United States. Furthermore, there is a large online opioid market, which enables customers to purchase unregulated opioids from the web [70, 71]. The increased availability of highly potent synthetic opioids, such as fentanyl and fentanyl analogues, has contributed to the dramatic increase in rates of overdose deaths since 2015 [19].

There has been substantial geographical variation in opioid misuse and overdose, which may be attributable to a range of factors [72]. Non-metropolitan areas are known to have higher rates of opioid prescribing [73], perhaps because the rural population disproportionately consists of older adults and people employed in physically demanding jobs who may be particularly susceptible to pain-related conditions [74-77]. Overdose deaths are more prevalent in non-metropolitan areas relative to urban areas [78].

Workplaces and schools are also important settings where individuals spend significant time. Some careers have particularly high rates of opioid misuse and are typically those characterised by demanding physical labour and/or easy access to opioids; individuals involved with construction occupations suffer from the highest rate of opioid overdose [79]. Schools are also an important setting, given that adolescence is a 
significant risk period and diversion of medication is common in this group [80].

Community norms with respect to alcohol, tobacco and drug use can also impact the likelihood of initiation of substance misuse [72,81]. Finally, drug disposal and collection sites can potentially deter misuse and discourage opioid diversion amongst patients' friends and family by restricting the available supply in households and communities [44].

Similarly, the availability and access to treatment are crucial for both the adequate management of health and mental health conditions that increase risks for opioid misuse (e.g. pain, psychiatric disorders) and for the effective treatment of OUD [82]. Despite ample evidence about effective medications for the treatment of OUD $[83,84]$, they remain widely underutilised in the United States $[85,86]$ due to misperceptions about the efficacy of medications [87], policy and regulatory barriers [88], and lack of access to addiction experts [89, 90], among others. Furthermore, access to care, and to evidence-based care, varies across regions. The availability of high-quality care is also impacted by societal factors (see below). OUD is associated with high rates of relapse and the type of care received has substantial implications for outcomes [91, 92].

\section{Societal level}

The major risk factors of opioid misuse are shaped by the larger social context, which encompass opioid supply and demand, government regulations, economic conditions and unemployment rates, elements of the media, social stigma, discrimination and prejudice, advertising campaigns, educational campaigns, and law enforcement.

The market economy of opioids is altered by the fluctuations in a drug's supply and demand. A tremendous increase in the supply and availability of opioids arose from the over-prescription, diversion and redistribution of the pills to family, friends and/or co-workers. This was exacerbated by pharmaceutical companies' extensive legal advertising tactics, which can lower consumers' perception of the risks of opioids and increase their knowledge on prescription drug availability [93, 94]. Over time, the epidemic intensified as illicit opioids flooded the market and heroin became inexpensive [82, 95] - heroin is only a third of its price in the 1990s and remains cheaper than opioid prescriptions [96]. Indeed, over $80 \%$ of people who initiate heroin use first started opioid use with prescription opioids [97]; cost is one of the most commonly reported reasons for this transition [98]. Opioid supply can be managed through reduced prescribing or increased use of misuse-deterrent formulations, but these efforts can be challenged by unintended, short-term negative consequences. In particular, the decreased availability of prescription opioid analgesics can lead to increases in the use of illicitly produced opioids such as heroin [67].

Government programmes and regulations related to opioids may take many forms such as drug scheduling through the Drug Enforcement Agency, regulation of opioid prescribing practices (e.g. use of Prescription Drug Monitoring Programs; PDMPs) [99] and Medicare/ Medicaid regulations. Data support the potential value of certain policies such as Good Samaritan laws [100], naloxone access legislation [101], and PDMP requirements [102]. Importantly, these different policies target different elements of the opioid crisis (e.g. overdose fatalities, prescribing practices). Government regulations also have implications for treatment availability, as federal and state governments regulate accreditation and licensing requirements as well as elements of training and service provision. For example, the Drug Addiction Treatment Act of 2000 requires that prescribers complete additional training to prescribe or dispense buprenorphine. Likewise, government regulations require that methadone is only dispensed in licensed opioid treatment programmes and cannot be used for the treatment of OUD in primary care, unlike in other countries.

The number of people who have health insurance coverage varies by state and has implications for access to OUD treatment. Medicaid expansion has played a significant role in access to medication for OUD; states that elected to expand Medicaid as part of the Affordable Care Act had a more than four-fold higher increase in prescribing of effective medications for OUD (specifically buprenorphine and naltrexone) relative to nonexpansion states [103]. In addition to their contributions to the opioid supply, payer policies also impact access to treatment for pain, psychiatric illness and OUD. For example, prior authorisation for buprenorphine prescribing has been presented as a strategy for reducing diversion or other adverse events; however, this can also present a significant barrier to care [104].

Social stigma, the misconception of substance misuse as a by-product of weak willpower and moral corruption, is a significant barrier to seeking help for opioid misuse $[3,49,105]$. Likewise, cultural and social beliefs communication via media and social media can be either harmful (e.g. influencing an increase in substance use) [106, 107] or protective (e.g. increase public awareness about opioids and their potential harms).

The rise in 'deaths of despair' (typically referring to overdose and suicide fatalities) between 1999 and 2015 has been linked to poor economic conditions [82, 108]. During macroeconomic slumps, every percentage point increase in unemployment saw a $3.6 \%$ rise in opioid death rates and emergency visits. The fall in the employment rate resulted in lower life satisfaction and higher 
drug use among the population [109, 110]. A recent working paper from the National Bureau of Economic Research concluded that $10 \%$ of the rise in opioidrelated deaths could be explained by recessions [111]. Nonetheless, macroeconomic impacts on drug use are complex due to the many variables affected by poor economic conditions (e.g. drug prices, incomes, employment, etc.) [112].

Law enforcement and the criminal justice systems are other significant components of the response to the opioid crisis. Law enforcement (along with other emergency responder groups) has been increasingly involved in overdose-rescue efforts. Some departments have expanded these efforts to include linkage to treatment and other supports. Law enforcement also plays a role in policing of the illicit opioid supply [113]. Finally, opioids are controlled substances that carry significant criminal penalties for possession and distribution. Substance use disorders are common among incarcerated people and release from prison is associated with a significantly heightened risk for fatal overdose [114]. Racial and ethnic minorities are disproportionately affected by the criminalisation of substance use, rather than a public health approach. Additionally, those recently released from prison were more likely to die from overdose than those who did not face the law enforcement $[82,115]$.

\section{Conclusion}

The primary goal of this article was to emphasise that the opioid crisis is a multi-faceted and ever-evolving issue, which requires the consideration of numerous interacting factors in developing interventions and evaluating their effectiveness. Although much of our focus in this paper is on recent findings and trends, it is essential to note that the devastating impact of opioid misuse and OUD has been ongoing for decades. The complex and interacting contributors have evolved over time, yet many have been longstanding across each of these levels (e.g. individual, community). These factors intersect with several disparate stakeholder groups, including healthcare providers, government and regulatory agencies, insurers, and law enforcement and criminal justice, among others.

Although we have organised our framework according to the individual, interpersonal, community and society contexts, we also recognise that there is substantial interconnectedness among these contexts. For example, access to opioids - a substantial contributor of likelihood of use - cuts across each of these contexts, including the individual (e.g. presence of a pain condition), interpersonal (e.g. access to opioids from family or friends), community (e.g. availability of drug disposal resources) and society (e.g. PDMP laws). The ultimate utility of this framework is to use it to investigate the complex and multi-directional links among the factors that contribute to the ongoing epidemic.

The development of effective opioid prevention and treatment interventions requires a broad analysis of the factors that arise from multiple contexts (individual, interpersonal, community and society). We conceptualised this complex system using the social-ecological framework presented in Fig. 1. As research continues to evolve on these factors and their contribution to the opioid epidemic, this framework can be further refined. The framework is also intended to provide context for the generation of testable hypotheses about these factors, their interaction and the impact of treatment or policy levers at each level on the opioid epidemic.

\section{Supplementary information}

Supplementary information accompanies this paper at https://doi.org/10. 1186/s12961-020-00596-8.

\section{Additional file 1.}

Abbreviations

OUD: Opioid use disorder; PDMP: Prescription Drug Monitoring Program

\section{Acknowledgements}

We would like to thank Miriam Boeri, Erin Stringfellow, Wayne Wakeland and Scott Weiner who provided constructive feedback on earlier versions of this article.

\section{Authors' contributions \\ Conceptualisation and design: MSJ, RKM; Writing the first draft: MSJ, RCH, and RKM; Discussion, critical review, and writing: MSJ, MB, RCH, HKK, and RKM. All authors read and approved the final manuscript.}

\section{Funding}

Not applicable.

Availability of data and materials

Not applicable.

Ethics approval and consent to participate

Not applicable.

Consent for publication

Not applicable.

\section{Competing interests}

The authors declare that they have no competing interests.

\section{Author details}

${ }^{1}$ Harvard Medical School, Harvard University, Boston, MA, United States of America. ${ }^{2}$ Institute for Technology Assessment, Massachusetts General Hospital, 101 Merrimac St, Suite 1010, Room 1032, Boston, MA 02114, United States of America. ${ }^{3}$ Grayken Center for Addiction, Boston Medical Center, Boston, MA, United States of America. ${ }^{4}$ T.H. Chan School of Public Health, Harvard University, Boston, MA, United States of America. ${ }^{5}$ Harvard Kennedy School, Harvard University, Cambridge, MA, United States of America.

${ }^{6}$ Division of Alcohol and Drug Abuse, McLean Hospital, Belmont, MA, United States of America. 
Received: 14 October 2019 Accepted: 29 June 2020

\section{Published online: 06 August 2020}

\section{References}

1. Center for Behavioral Health Statistics and Quality. Results from the 2017 National Survey on Drug Use and Health: Detailed Tables. U.S. Health and Human Services; 2018.

2. Scholl $L$, et al. Drug and opioid-involved overdose deaths - United States, 2013-2017. Morb Mortal Wkly Rep. 2018;67(5152):1419-27.

3. Gomes T, et al. The burden of opioid-related mortality in the United States. JAMA Netw Open. 2018;1(2):e180217.

4. Office of Adolescent Health, Opioids and Adolescents, U.S. Washington, D.C: Department of Health and Human Services; 2017. https://www.hhs.gov/ash/ oah/adolescent-development/substance-use/drugs/opioids/index.html. Accessed 15 Jul 2020.

5. Bart G. Maintenance medication for opiate addiction: the foundation of recovery. J Addict Dis. 2012;31(3):207-25.

6. Hser YI, Anglin D, Powers K. A 24-year follow-up of California narcotics addicts. Arch Gen Psychiatry. 1993;50(7):577-84.

7. Bronfenbrenner U. The ecology of human development. Cambridge: Harvard University Press; 1979.

8. Connell CM, et al. Social-ecological influences on patterns of substance use among non-metropolitan high school students. Am J Community Psychol. 2010;45(1-2):36-48.

9. Sudhinaraset M, Wigglesworth C, Takeuchi DT. Social and cultural contexts of alcohol use: influences in a social-ecological framework. Alcohol Res Curr Rev. 2016;38(1):35-45.

10. Abuse S, Mental Health Services Administration. The DAWN report: highlights of the 2011 Drug Abuse Warning Network (DAWN) findings on drug-related emergency department visits. Rockville: US Department of Health and Human Services. Substance Abuse and Mental Health Services Administration, Center for Behavioral Health Statistics and Quality; 2013. p. 64-72.

11. Schepis TS, Hakes JK. Age of initiation, psychopathology, and other substance use are associated with time to use disorder diagnosis in persons using opioids nonmedically. Subst Abus. 2017;38(4):407-13.

12. Hirschtritt ME, Delucchi KL, Olfson M. Outpatient, combined use of opioid and benzodiazepine medications in the United States, 1993-2014. Prev Med Rep. 2018;9:49-54.

13. Cicero TJ, et al. Co-morbidity and utilization of medical services by pain patients receiving opioid medications: data from an insurance claims database. Pain. 2009;144(1-2):20-7.

14. Comer SD, et al. Evaluation of potential sex differences in the subjective and analgesic effects of morphine in normal, healthy volunteers. Psychopharmacology. 2010;208(1):45.

15. Lind JN, et al. Maternal use of opioids during pregnancy and congenital malformations: a systematic review. Pediatrics. 2017;139:e20164131.

16. Terrell KM, et al. Analgesic prescribing for patients who are discharged from an emergency department. Pain Med. 2010;11(7):1072-7.

17. Anderson KO, Green CR, Payne R. Racial and ethnic disparities in pain: causes and consequences of unequal care. J Pain 2009. 10(12): p. 1187-1204.

18. Wu LT, Zhu H, Swartz MS. Treatment utilization among persons with opioid use disorder in the United States. Drug Alcohol Depend. 2016;169:117-27.

19. Seth $P$, et al. Overdose deaths involving opioids, cocaine, and psychostimulants_-United States, 2015-2016. Am J Transplant. 2018;18(6): 1556-68.

20. Hansen $\mathrm{H}$, et al. Buprenorphine and methadone treatment for opioid dependence by income, ethnicity and race of neighborhoods in New York City. Drug Alcohol Depend. 2016;164:14-21.

21. Stein BD, et al. A population-based examination of trends and disparities in medication treatment for opioid use disorders among Medicaid enrollees. Subst Abus. 2018;39(4):419-25.

22. Krawczyk N, et al. Racial and ethnic differences in opioid agonist treatment for opioid use disorder in a U.S. national sample. Drug Alcohol Depend. 2017;178:512-8.

23. Boudreau DM, et al. Documented opioid use disorder and its treatment in primary care patients across six U.S. health systems. J Subst Abus Treat. 2020;112s:41-8

24. Weiss RD, et al. Reasons for opioid use among patients with dependence on prescription opioids: the role of chronic pain. J Subst Abus Treat. 2014; 47(2):140-5.
25. Conway KP, et al. Lifetime comorbidity of DSM-IV mood and anxiety disorders and specific drug use disorders: results from the National Epidemiologic Survey on Alcohol and Related Conditions. J Clin Psychiatry. 2006;67(2):247-57.

26. Sullivan MD, et al. Association between mental health disorders, problem drug use, and regular prescription opioid use. Arch Intern Med. 2006; 166(19):2087-93.

27. Turk DC, Swanson KS, Gatchel RJ. Predicting opioid misuse by chronic pain patients: a systematic review and literature synthesis. Clin J Pain 2008. 24(6): p. 497-508.

28. Morley Kl, et al. Polysubstance use and misuse or abuse of prescription opioid analgesics: a multi-level analysis of international data. Pain. 2017; 158(6):1138-44

29. Cicero TJ, Ellis MS, Kasper ZA. Polysubstance use: a broader understanding of substance use during the opioid crisis. Am J Public Health 2020. 110(2): p. $244-250$.

30. Schultz W. Potential vulnerabilities of neuronal reward, risk, and decision mechanisms to addictive drugs. Neuron. 2011;69(4):603-17.

31. Swendsen J, Le Moal M. Individual vulnerability to addiction. Ann N Y Acad Sci. 2011;1216(1):73-85.

32. Nelson EC, et al. Association of OPRD1 polymorphisms with heroin dependence in a large case-control series. Addict Biol. 2014;19(1):111-21.

33. Gao $X$, et al. Contribution of genetic polymorphisms and haplotypes in DRD2, BDNF, and opioid receptors to heroin dependence and endophenotypes among the Han Chinese. Omics. 2017;21(7):404-12.

34. Van Ree JM, Gerrits MA, Vanderschuren LJ. Opioids, reward and addiction: an encounter of biology, psychology, and medicine. Pharmacol Rev. 1999; 51(2):341-96.

35. Northrup TF, et al. Opioid withdrawal, craving, and use during and after outpatient buprenorphine stabilization and taper: a discrete survival and growth mixture model. Addict Behav. 2015;41:20-8.

36. Aklin WM, et al. Risk-taking propensity as a predictor of induction onto naltrexone treatment for opioid dependence. J Clin Psychiatry. 2012;73(8): e1056-61.

37. Hammarlund R, et al. Review of the effects of self-stigma and perceived social stigma on the treatment-seeking decisions of individuals with drugand alcohol-use disorders. Subst Abus Rehabil. 2018;9:115-36.

38. Ayres $\mathrm{R}$, et al. Enhancing motivation within a rapid opioid substitution treatment feasibility RCT: a nested qualitative study. Subst Abuse Treat Prev Policy. 2014;9(1):44.

39. Langabeer J, et al. Outreach to people who survive opioid overdose: linkage and retention in treatment. J Subst Abus Treat. 2020;111:11-5.

40. Blanchard KA, et al. Motivational subtypes and continuous measures of readiness for change: concurrent and predictive validity. Psychol Addict Behav. 2003;17(1):56.

41. Gossop M, Stewart D, Marsden J. Readiness for change and drug use outcomes after treatment. Addiction. 2007;102(2):301-8.

42. Collins $D$, et al. Non-medical use of prescription drugs among youth in an Appalachian population: prevalence, predictors, and implications for prevention. J Drug Educ. 2011;41(3):309-26.

43. Schroeder RD, Ford JA. Prescription drug misuse: a test of three competing criminological theories. J Drug Issues. 2012;42(1):4-27.

44. Substance abuse and mental health services administration, preventing prescription drug misuse. Overview of factors and strategies; 2016. https:// preventionsolutions.edc.org/sites/default/files/attachments/Preventing-PrescriptionDrug-Misuse-Overview-Factors-Strategies_0.pdf. Accessed 15 Jul 2020.

45. Mistry J, et al. Genetics of opioid dependence: a review of the genetic contribution to opioid dependence. Curr Psychiatr Rev. 2014;10(2):156-67. https://preventionsolutions.edc.org/sites/default/files/attachments/ Preventing-Prescription-Drug-Misuse-Overview-Factors-Strategies_0.pdf.

46. Silva $\mathrm{K}$, et al. Factors associated with history of non-fatal overdose among young nonmedical users of prescription drugs. Drug Alcohol Depend. 2013; 128(1-2):104-10.

47. Pickens RW, et al. Family history influence on drug abuse severity and treatment outcome. Drug Alcohol Depend. 2001;61(3):261-70.

48. Powis $B$, et al. The differences between male and female drug users: community samples of heroin and cocaine users compared. Subst Use Misuse. 1996;31(5):529-43.

49. Hewell VM, Vasquez AR, Rivkin ID. Systemic and individual factors in the buprenorphine treatment-seeking process: a qualitative study. Subst Abuse Treat Prev Policy. 2017;12(1):3. 
50. Jones CM, Paulozzi $L$, Mack KA. Sources of prescription opioid pain relievers by frequency of past-year nonmedical use: United States, 2008-2011. JAMA Intern Med 2014; 174(5): p. 802-803.

51. SAMHSA, National survey on drug use and health: 2013 dress rehearsal final report U.S.H.a.H. Services, Editor. 2014. https://www.samhsa.gov/data/sites/ default/files/NSDUH-DressRehearsal-2013/NSDUH-DressRehearsal-2013.pdf.

52. Albrecht $\mathrm{S}$. The opiate addict in your office, heroin and pain pills in your workplace? Psychology Today. 2014. https://www.psychologytoday.com/us/ blog/the-act-violence/201402/the-opiate-addict-in-your-office. Accessed 15 Dec 2018.

53. Stumbo SP, et al. A qualitative analysis of family involvement in prescribed opioid medication monitoring among individuals who have experienced opioid overdoses. Subst Abus. 2016:37(1):96-103.

54. Gyarmathy VA, Latkin CA. Individual and social factors associated with participation in treatment programs for drug users. Subst Use Misuse. 2008; 43(12-13):1865-81.

55. Daley DC. Family and social aspects of substance use disorders and treatment. J Food Drug Anal. 2013;21(4):S73-6.

56. Center for Disease control and Prevention, The social-ecological model: a framework for prevention. 2018, Center for Disease Control and Prevention.

57. Schieber LZ, et al. Trends and patterns of geographic variation in opioid prescribing practices by State, United States, 2006-2017. JAMA Netw Open. 2019;2(3):e190665.

58. Upshur CC, Luckmann RS, Savageau JA. Primary care provider concerns about management of chronic pain in community clinic populations. J Gen Intern Med. 2006;21(6):652-5.

59. O'rorke JE, et al. Physicians' comfort in caring for patients with chronic nonmalignant pain. Am J Med Sci. 2007;333(2):93-100.

60. Volkow ND, McLellan AT. Opioid abuse in chronic pain-misconceptions and mitigation strategies. N Engl J Med. 2016;374(13):1253-63.

61. Kolodny A, et al. The prescription opioid and heroin crisis: a public health approach to an epidemic of addiction. Annu Rev Public Health. 2015;36: 559-74.

62. Makary MA, Overton HN, Wang P. Overprescribing is major contributor to opioid crisis. BMJ. 2017;359:j4792.

63. Bohnert ASB, Guy GP Jr, Losby JL. Opioid prescribing in the United States before and after the Centers for Disease Control and Prevention's 2016 Opioid Guideline. Ann Intern Med. 2018;169(6):367-75.

64. The more opioids doctors prescribe, the more they get paid. Harvard T.H. School of Public Health 2018. https://www.hsph.harvard.edu/news/hsph-inthe-news/opioids-doctors-prescriptions-payments/. Accessed 11 Jul 2020.

65. Dhalla IA, Persaud N, Juurlink DN. Facing up to the prescription opioid crisis. BMJ. 2011:343:d5142.

66. DeJong C, et al. Pharmaceutical industry-sponsored meals and physician prescribing patterns for Medicare beneficiaries. JAMA Intern Med. 2016; 176(8):1114-22.

67. Leece P. Tamper-resistant drugs cannot solve the opioid crisis. CMAJ. 2015; 187:717-8.

68. Nelson LS, Juurlink DN, Perrone J. Addressing the opioid epidemic. JAMA. 2015;314(14):1453-4.

69. Clinton Foundation, The opioid epidemic from evidence to impact. 2017. https://www.jhsph.edu/events/2017/americas-opioid-epidemic/report/2017JohnsHopkins-Opioid-digital.pdf. Accessed 11 Jul 2020.

70. The National Center on Addiction and Substance Abuse at Columbia University. You've Got Drugs!. Prescription Drug Pushers on the Internet. 2004. https://www.centeronaddiction.org/download/file/fid/556.

71. Forman RF. Availability of opioids on the internet. JAMA. 2003;290(7):889.

72. Keyes $\mathrm{KM}$, et al. Understanding the rural-urban differences in nonmedical prescription opioid use and abuse in the United States. Am J Public Health. 2014;104(2):e52-9.

73. McDonald DC, Carlson K, Izrael D. Geographic variation in opioid prescribing in the US. J Pain. 2012;13(10):988-96.

74. Glasgow N. Rural/urban patterns of aging and caregiving in the United States. J Fam Issues. 2000;21(5):611-31.

75. Hunsucker SC, Frank DI, Flannery J. Meeting the needs of rural families during critical illness: The APN's role. Dimens Crit Care Nurs. 1999;18(3):24.

76. Hoffman PK, Meier BP, Council JR. A comparison of chronic pain between an urban and rural population. J Community Health Nurs. 2002;19(4):21324.

77. Leff $M$, et al. Comparison of urban and rural non-fatal injury: the results of a statewide survey. Inj Prev. 2003;9(4):332-7.
78. Paulozzi LJ, Xi Y. Recent changes in drug poisoning mortality in the United States by urban-rural status and by drug type. Pharmacoepidemiol Drug Saf. 2008;17(10):997-1005.

79. Harduar LM, Steege AL, Luckhaupt SE. Occupational patterns in unintentional and undetermined drug-involved and opioid-involved overdose deaths - United States, 2007-2012. Morb Mortal Wkly Rep. 2018; 67(33):925-30

80. Boyd CJ, et al. Prescription drug abuse and diversion among adolescents in a southeast Michigan school district. Arch Pediatr Adolesc Med. 2007;161(3): 276-81.

81. Musick K, Seltzer JA, Schwartz CR. Neighborhood norms and substance use among teens. Soc Sci Res. 2008:37(1):138-55.

82. National Academies of Sciences Engineering and Medicine. Pain management and the opioid epidemic: balancing societal and individual benefits and risks of prescription opioid use. Washington, DC: National Academies Press; 2017.

83. Wakeman SE, et al. Comparative effectiveness of different treatment pathways for opioid use disorder. JAMA Netw Open. 2020;3(2):e1920622.

84. Connery HS. Medication-assisted treatment of opioid use disorder: review of the evidence and future directions. Harvard Rev Psychiatr. 2015;23(2):63-75.

85. Volkow ND, et al. Medication-assisted therapies — tackling the opioidoverdose epidemic. N Engl J Med. 2014;370(22):2063-6.

86. Larochelle MR, et al. Medication for opioid use disorder after nonfatal opioid overdose and association with mortality: a cohort study. Ann Intern Med. 2018:169(3):137-45.

87. Knudsen HK, Abraham AJ, Roman PM. Adoption and implementation of medications in addiction treatment programs. J Addict Med. 2011:5(1):21-7.

88. Clark RE, Baxter JD. Responses of state Medicaid programs to buprenorphine diversion: doing more harm than good? JAMA Intern Med. 2013;173(17):1571-2

89. Deflavio JR, et al. Analysis of barriers to adoption of buprenorphine maintenance therapy by family physicians. Rural Remote Health. 2015;15: 3019.

90. Knudsen HK, Roman PM, Oser CB. Facilitating factors and barriers to the use of medications in publicly funded addiction treatment organizations. J Addict Med. 2010:4(2):99-107.

91. McGlynn EA, et al. The quality of health care delivered to adults in the United States. N Engl J Med. 2003;348(26):2635-45.

92. Nunes EV, et al. Relapse to opioid use disorder after inpatient treatment: protective effect of injection naltrexone. J Subst Abuse Treat. 2018:85:49-55.

93. Nunes, E.V., et al., Relapse to opioid use disorder after inpatient treatment: Protective effect of injection naltrexone. J Subst Abuse Treat. 2018;85:49-55. https://doi.org/10.1016/j.jsat.2017.04.016.

94. Strasburger VC. Policy statement--children, adolescents, substance abuse, and the media. Pediatrics. 2010;126(4):791-9.

95. Compton WM, Jones CM, Baldwin GT. Relationship between nonmedical prescription-opioid use and heroin use. N Engl J Med 2016. 374(2): p. 154163.

96. Felter C. The US Opioid Epidemic. 2017 Council on Foreign Relations. https://www.cfr.org/backgrounder/us-opioid-epidemic. Accessed11 Jul 2020.

97. Jones CM. Heroin use and heroin use risk behaviors among nonmedical users of prescription opioid pain relievers-United States, 2002-2004 and 2008-2010. Drug Alcohol Depend. 2013;132(1):95-100.

98. Cicero TJ, et al. The changing face of heroin use in the United States: a retrospective analysis of the past 50 years. JAMA Psychiatry. 2014;71(7):8216.

99. Haffajee RL, Jena $A B$, Weiner SG. Mandatory use of prescription drug monitoring programs. JAMA. 2015;313(9):891-2.

100. McClellan C, et al. Opioid-overdose laws association with opioid use and overdose mortality. Addict Behav. 2018;86:90-5.

101. Gertner AK, Domino ME, Davis CS. Do naloxone access laws increase outpatient naloxone prescriptions? Evidence from Medicaid. Drug Alcohol Depend. 2018;190:37-41.

102. Strickler GK, et al. Effects of mandatory prescription drug monitoring program (PDMP) use laws on prescriber registration and use and on risky prescribing. Drug Alcohol Depend. 2019;199:1-9.

103. Sharp A, et al. Impact of Medicaid expansion on access to opioid analgesic medications and medication-assisted treatment. Am J Public Health. 2018; 108(5):642-8.

104. Kermack $A$, et al. Buprenorphine prescribing practice trends and attitudes among New York providers. J Subst Abus Treat. 2017;74:1-6. 
105. Olsen Y, Sharfstein JM. Confronting the stigma of opioid use disorder-and its treatment. JAMA. 2014;311(14):1393-4.

106. Hawton $\mathrm{K}$, et al. Effects of a drug overdose in a television drama on presentations to hospital for self poisoning: time series and questionnaire study. BMJ. 1999;318(7189):972-7.

107. Moreno MA, et al. Display of health risk behaviors on MySpace by adolescents: prevalence and associations. Arch Pediatr Adolesc Med. 2009; 163(1):27-34.

108. Case A, Deaton A. Mortality and morbidity in the 21st century. Brook Pap Econ Act. 2017;2017:397.

109. Hollingsworth A, Ruhm CJ, Simon K. Macroeconomic conditions and opioid abuse. J Health Econ. 2017;56:222-33.

110. Nagelhout $\mathrm{GE}$, et al. How economic recessions and unemployment affect illegal drug use: a systematic realist literature review. Int J Drug Policy. 2017; 44:69-83.

111. Ruhm CJ. Deaths of despair or drug problems? Working Papers 24188 , National Bureau of Economic Research, Inc. 2018. https://ideas.repec.org/p/ nbr/nberwo/24188.html. Accessed $15 \mathrm{Jul} 2020$.

112. Bretteville-Jensen AL. Illegal drug use and the economic recession--what can we learn from the existing research? Int J Drug Policy. 2011;22(5):353-9.

113. U.S. Immigration and Customs Enforcement, Combatting the Opioid Crisis D.o.H. Security, Editor. 2018, U.S. Immigration and Customs Enforcement. https://www.ice.gov/features/opioid-crisis. Accessed 15 Aug 2019.

114. Binswanger IA, et al. Release from prison - a high risk of death for former inmates. N Engl J Med. 2007;356(2):157-65.

115. Fellner J. Race, drugs, and law enforcement in the United States. Stanford Law Policy Rev. 2009;20:257.

\section{Publisher's Note}

Springer Nature remains neutral with regard to jurisdictional claims in published maps and institutional affiliations.

Ready to submit your research? Choose BMC and benefit from:

- fast, convenient online submission

- thorough peer review by experienced researchers in your field

- rapid publication on acceptance

- support for research data, including large and complex data types

- gold Open Access which fosters wider collaboration and increased citations

- maximum visibility for your research: over $100 \mathrm{M}$ website views per year

At $\mathrm{BMC}$, research is always in progress.

Learn more biomedcentral.com/submissions 